\title{
Géohistoire et géoarchéologie des territoires forestiers limousins
}

Philippe Allée

\section{OpenEdition \\ Journals}

Édition électronique

URL : http://journals.openedition.org/adlfi/7280

ISSN : 2114-0502

Éditeur

Ministère de la culture

Référence électronique

Philippe Allée, "Géohistoire et géoarchéologie des territoires forestiers limousins », ADLFI. Archéologie de la France - Informations [En ligne], Limousin, mis en ligne le 01 mars 2007, consulté le 02 mai 2019. URL : http://journals.openedition.org/adlfi/7280

Ce document a été généré automatiquement le 2 mai 2019.

(C) Ministère de la Culture et de la Communication, CNRS 


\title{
Géohistoire et géoarchéologie des territoires forestiers limousins
}

\author{
Philippe Allée
}

\author{
Identifiant de l'opération archéologique : 2752 \\ Date de l'opération : 2007 (PC) \\ Inventeur(s) : Allée Philippe (SUP)
}

1 Le Limousin est un territoire forestier original, dont l'histoire complexe se devine dans ses paysages actuels. Les massifs forestiers y sont hétérogènes et morcelés, formés d'une mosaïque mêlant futaies anciennes de feuillus et jeunes futaies résineuses; taillis de chênes, de châtaigniers et de hêtres ; accrues multiformes... Ces forêts conservées, remodelées, créées ex nihilo à partir d'essences introduites plantées ou régénérées par accrues spontanées, traduisent une longue et complexe histoire des relations hommeforêt. Depuis 2005, un PCR réunissant archéologues et historiens, géographes et forestiers, écologues et paléobotanistes est consacré à l'étude géohistorique et archéologique de cette forêt limousine. Dans ces travaux pluridisciplinaires, la forêt n'est pas appréhendée comme un écosystème naturel modifié par l'homme, mais comme un véritable anthroposylvosystème produit et géré par l'homme, territoire approprié, enjeu économique et politique, objet de réglementation et de conflit, espace de projection mentale et d'identification. D'abord consacrée au seul territoire de la châtaigneraie limousine, la problématique s'est élargie progressivement à l'ensemble de la région, au travers de plusieurs fenêtres géographiques ouvertes dans contextes géographiques et forestiers variés. Quatre ateliers thématiques ont alors été retenus: les héritages forestiers dans le territoire d'aujourd'hui; la forêt dans les paysages du passé; l'archéologie de la forêt limousine; forêt et fonctionnement socioéconomique des territoires.

Le rapport intermédiaire, rédigé à l'issue d'une première année de travail, a insisté sur les travaux conduits dans deux des quatre ateliers thématiques proposés dans le projet triennal 2007-2009. C'est en effet dans les ateliers 2 et 3, consacrés à l'histoire des 
paysages forestiers passés et à l'archéologie forestière que les avancées scientifiques ont été les plus importantes et les plus intéressantes.

\section{Approche historique des paysages forestiers passés}

\section{Un important corpus documentaire sur l'évolution contemporaine (s.s.) des châtaigneraies (vergers et taillis).}

Les travaux d'inventaire conduits cette année par Pascal Plas ont révélé que les historiens contemporanéistes disposent, pour la période qui court des années 1880/90 jusqu'à la Seconde guerre mondiale, d'un ensemble de sources très abondantes se rapportant au châtaignier dans les espaces qui occupent l'enquête. Il s'agit de documents de différente nature, de très nombreux articles, études, monographies, brochures et d'un fond d'archives relevant d'une myriade d'organismes se rapportant aux forêts, à l'économie de celles-ci et à différentes espèces sylvestres dont le châtaignier considéré alors comme le plus menacé.

4 La plupart de ces écrits sont en effet corrélatifs à la constatation d'un premier « déclin de la châtaigneraie » à la fin du XIX ${ }^{\mathrm{e}}$ s. puis à l'observation de " la mort de la châtaigneraie » dès lors qu'elle est touchée par la maladie de l'encre au XXe $\mathrm{s}$. Une prose abondante résulte des tentatives de sauvetage de l'arbre, de la plantation de nouvelles espèces exogènes et d'une nouvelle économie du châtaignier qui se met en place à la veille de la Seconde guerre.

5 De nombreux textes parus entre 1880 et 1930 relèvent d'une approche littéraire du châtaignier, que l'on qualifiera d'affective, dans laquelle l'arbre est considéré comme un élément essentiel de la "culture limousine ", élément menacé tant par la maladie de l'encre que par des évolutions sourdes de modes de vie qui le condamnent à la relégation ; certains auteurs vont jusqu'à évoquer la fin d'une « civilisation de la châtaigne », concept qui correspond à des formes d'économies rurales spécifiques dans lesquelles la place de l'arbre, et de son fruit surtout, était essentielle à la survie même du groupe. Ainsi naquit probablement le mythe de la châtaigne « fruit salvateur des Limousins » dans les périodes de disette et de famines...

6 Les écrits restants - la majorité - sont en réalité des études scientifiques de grande qualité qui se développent dans les sociétés savantes de la région, au sein des milieux professionnels des écoles d'agriculture et forestières, dans le groupe des ingénieurs des Eaux et Forêts ainsi que dans les milieux érudits de la colonie limousine de Paris qui «pense» son terroir natal, ses «petites patries» en terme de développement futur.

7 C'est en 1885 que Paul Garrigou-Lagrange créa à Limoges une société scientifique à laquelle il donna le nom du grand physicien Gay Lussac, organisme qui, entre autres choses s'intéressa à l'arbre et au châtaignier en particulier. A partir de cette initiative et dans son prolongement quoique dans des contextes différents, des structures d'étude et de protection des châtaigneraies, des associations et sociétés de mise en valeur des produits de l'arbre, de reboisement et de réflexion culturale, des laboratoires de recherche et des stations agriculturales se multiplièrent. Toutes ont laissé une multitude de papiers qui n'ont guère été exploités à ce jour. On peut ajouter enfin à cet ensemble déjà conséquent les archives privées de tous ceux qui furent à un moment ou à un autre 
les promoteurs d'actions spécifiques en faveur de la châtaigneraie ou, plus généralement du reboisement et qui se retrouvent à intervalles réguliers dans des colloques et congrès relatifs aux questions forestières ; dès avant la guerre de 1914, de nombreux acteurs du monde économique et politique se sont penchés sur la question des ressources forestières et, au sein de ces dernières, sur le châtaignier en particulier puisque ce dernier apparaissait comme le plus menacé ; des parlementaires, des dirigeants de chambres de commerce et de chambres de métiers, des responsables agricoles et de sociétés forestières, etc., prirent acte à la veille de la Première guerre de ce qu'ils nommèrent euxmêmes «le problème du châtaignier ", suscitèrent des études historiques, firent réaliser des bilans et des états et proposèrent des solutions pour une « autre châtaigneraie ». Les «sources politiques» de la question du châtaignier sont loin d'être négligeables dans la mesure où les parlementaires, en particulier les élus des "terres de castanides", sont nécessaires à la mise en place d'une législation favorable à l'entretien, à la conservation et au développement de la forêt.

Ce corpus de sources, divers mais cohérent, dont on vient, rapidement, de faire état ici est riche d'intérêt. Ces débats et écrits multiples sont une aubaine pour l'historien; bien documentés et rédigés par des spécialistes, par ailleurs bon connaisseurs des terroirs et des pratiques, ils font référence à un ensemble de rapports et de notes antérieurs auxquels nous n'avons plus accès aujourd'hui et qui permettent de reconstituer des situations de la châtaigneraie des dernières années du XVIII ${ }^{\mathrm{e}} \mathrm{s}$. jusqu'au début de la troisième République.

\section{Une avancée des connaissances sur la période médiévale}

9 Tout un questionnement, conduit par D. Glomot et R. Crouzevialle, est réalisé autour du problème de la forêt médiévale: une approche croisée, mêlant étude des textes, cartographie et toponymie permet de répondre aux interrogations suivantes.

- Quelle est la morphologie et quelle est la composition des parcelles boisées ? La forêt est-elle la relique d'un massif ancien ayant survécu à la poussée anthropique ou bien est-elle l'oeuvre de l'homme, planteur et sélectionneur des essences?

- Où se localisent ces parcelles et quelle part du terroir occupent-elles, à l'échelle du finage et à l'échelle de la région? Dans l'hypothèse d'un boisement compris entre $25 \%$ et $30 \%$ du territoire, faut-il imaginer seulement des massifs arborés ceinturant les finages, ou distinguer un vaste éventail de types de boisements (en périphérie, en altitude, sur certains versants, etc.) ?

- Peut-on établir une typologie du boisement, allant de l'arbre isolé jusqu'au massif de haute futaie, en passant par la haie, le verger et le taillis? Quels sont les critères à prendre en compte (altitude, hydrologie, exposition, superficie, pédologie, etc.) et quel est le rôle des hommes du Moyen Âge dans la structuration des espaces boisés?

- Quelle est la place de chaque type de boisement dans l'agrosystème et quelles interactions peut-on constater ? Existe-t-il des rotations spécifiques, des baux à clauses particulières, des droits d'usage, etc. ? Le défrichement, poncif de l'histoire agraire médiévale, doit-il être reconsidéré? En effet, l'idée d'une forêt originelle attaquée par une vaste poussée démographique est une conception peut-être trop mécanique: un défrichement peut intervenir sur un massif récent, lui-même successeur d'un terroir cultivé. 
- Enfin, comment est gérée la forêt et qui la possède ? Apparaît alors la notion de propriété féodale, celle du seigneur, et de propriété utile, celle du tenancier, avec tous les problèmes de mise en défens, de droit d'accès, de fiscalité, de reconnaissance et de transmission qui en découlent. La possession de l'arbre ou du massif d'arbres est-elle un élément de distinction socio-économique? manuscrits, puis par une phase d'étude statistique, pour établir la norme et l'exception. Par exemple, quel est le nombre moyen de parcelles boisées par seigneurie et quelle est la taille moyenne d'un bois, afin de repérer ensuite les domaines richement dotés en boisement et les gros propriétaires forestiers.

Dans un deuxième temps viennent la cartographie et l'étude spatiale, souvent négligées par les historiens. Cette étape doit permettre d'aboutir à un essai de restitution du paysage passé, afin de mieux comprendre son fonctionnement et de mettre en évidence les mutations environnementales et agraires depuis plus de six siècles. Des éléments purement géographiques, comme le rôle de la pente, de l'hydrographie, la qualité des sols, la localisation par rapport aux voies commerciales et aux centres urbains, ou la situation à l'intérieur du finage sont autant de notions ignorées le plus souvent dans les documents médiévaux: en rapprochant les différentes méthodes, ces lacunes peuvent être partiellement comblées. On dépasse la simple interprétation textuelle pour arriver à une compréhension globale.

\section{Archéologie de la forêt combustible limousine}

12 L'objectif de cet atelier est de poursuivre l'étude archéologique de la forêt combustible à partir des vestiges de charbonnières fossilisés sur les anciennes plates-formes de charbonnage conservées en forêt. Plusieurs objectifs ont été menés de front durant cette première année :

- poursuite des prospections de plates-formes de charbonnage ;

- acquisition des premières datations radiocarbone;

- travail de détermination en laboratoire du corpus anthracologique réuni ;

- mise en chantier d'une démarche expérimentale (reconstitution de charbonnières) permettant de combiner approche anthracologique et dendrométrique (mise au point d'une méthode dendrométrique permettant de reconstituer la taille des bois composant la charbonnière au moment de sa conception).

\section{L'inventaire}

En 2007 la prospection de charbonnières a été poursuivie dans plusieurs massifs forestiers. L'ensemble des nouvelles découvertes grossit l'effectif des platesformes de charbonnages connues et référencées à plus de six cent sur l'ensemble du territoire investi par le PCR : un peu plus de cinq cent pour la haute Dordogne, une centaine pour la châtaigneraie limousine. Ces découvertes confirment donc l'ampleur du charbonnage dans les massifs boisés limousins, qui semble avoir été historiquement une pratique courante dans l'ensemble des territoires forestiers. Elles révèlent le formidable potentiel scientifique offert par ces archives de terrain dans le domaine de l'archéologie forestière. La mise en évidence de ce riche ensemble documentaire est un fait inédit en Limousin. 
$14 \mathrm{Au}$ sud-ouest de la forêt limousine, des prospections ont été conduites (J.-G. Peyrony) dans la forêt du Châtenet, où de nombreux vestiges d'une métallurgie antique sont connus : découverte de ferriers ou de zones de dépôt de scories, de fragments de parois de four, etc. C'est là que se trouve notamment le site de La Morinie, où des fouilles ont mis en évidence ces dernières années un habitat rural lié à l'artisanat du fer, daté du $\mathrm{I}^{\mathrm{er}} \mathrm{s}$. au tout début du IV $\mathrm{e}$ s. apr. J-C. (fouilles Peyrony, 1996 à 1999). Les premiers résultats sont encourageants car plus de trente charbonnières ont été recensées dans une zone de faible surface, aux abords du gisement de La Morinie. Des datations radiocarbone seront entreprises prochainement afin de déterminer si certaines d'entre elles sont des vestiges liés à la paléométallurgie antique ou à des périodes postérieures.

Les autres massifs forestiers prospectés (P. Allée, M. Lehéricy, S. Paradis) dans la châtaigneraie limousine sont la forêt de Fayat et les forêts de pentes qui s'étirent le long de la vallée de la Dronne, dans l'environnement d'une série de forges échelonnées d'amont en aval le long de la rivière.

Le très important travail d'inventaire et d'analyse entrepris par R. Rouaud dans la vallée de la Dordogne s'est également poursuivi. Il s'agit ici d'un ancien territoire forestier destiné à la production de bois (merrains, carrassonnes et échalas) et de charbons de bois. Ces produits étaient acheminés vers Bergerac et Bordeaux par flottage et par gabares sur la rivière Dordogne. Sur les vingt et un secteurs parcourus durant l'année 2007 (environ 1100 ha de forêts de pente), cinq seulement n'ont pas révélé d'indice de charbonnage ancien. L'extension de la forêt charbonnée semble ainsi s'étendre à l'intégralité du bassin de la haute vallée de la Dordogne, soit des sources aux zones les plus à l'aval, composant ainsi un ensemble de charbonnières s'échelonnant de $1400 \mathrm{~m}$ à $250 \mathrm{~m}$ d'altitude et riche de plusieurs milliers de plates-formes.

Une prospection systématique a été entreprise sur les versants de la Luzège dans la commune de Lamazière-Basse. Sur 600 ha de forêts de pente, trois cent vingt platesformes on été référencées par GPS, et décrites morphologiquement, mais les nombreux retours sur le terrain pour la réalisation de sondage, ont révélé chaque fois l'existence de plates-formes inconnues. Cela nous donne à penser que sur l'ensemble des pentes de la Luzège la densité de plates-formes de charbonnage approche en moyenne l'unité à l'hectare avec des secteurs de forte concentration arrivant jusqu'à cinq. Ces plates-formes s'organisent en deux grands groupes morphologiques, des petites de $2 \mathrm{~m}$ à $3 \mathrm{~m}$ de diamètre et des plus grandes de $5 \mathrm{~m}$ à $7 \mathrm{~m}$.

18 Cet important corpus, ces traces encore bien visibles dans les pentes, amènent à s'interroger sur la méconnaissance de cette activité. En effet malgré l'omniprésence des indices, les charbonniers, leur métier et modes de vies, restent un champ ethnologique encore peu, voire pas du tout exploré sur la vallée de la Dordogne et le Limousin en général.

\section{Premiers résultats chronologiques et anthracologiques}

19 Le choix des premières plates-formes datées s'est fait dans le souci de couvrir le plus largement possible le territoire de la châtaigneraie sur lequel nous possédions des indices de charbonnage. Les datations ont été réalisées par la méthode du radiocarbone, au laboratoire d'analyse isotopique d'Athens of Georgia aux Etats-Unis. Les premiers 
résultats, concernant une vingtaine de charbonnières, nous informent que l'activité de charbonnage sur la châtaigneraie limousine comme dans la vallée de la Dordogne a duré au moins cinq siècles, de la moitié $d u X^{e}$ s. à la moitié $d u X X^{e} s$. Toutefois le pic d'activité semble se situer aux XVIII ${ }^{e}$ s. et XIX ${ }^{e}$ s. correspondant aux temps forts de l'activité des forges et du commerce fluvial sur la Dordogne.

Les analyses anthracologiques des charbonnières sont en cours. Si une présentation détaillée des résultats reste prématurée, quelques informations intéressantes méritent d'ores et déjà d'être évoquées.

Dans la vallée de la Dordogne, les analyses anthracologiques font ressortir au premier chef une récurrence de l'emploi du chêne (sessile ou pédonculé), couplé très souvent au charme, Carpinus betulus. Cette dernière essence semble être plus présente sur les orientations à bonne hygrométrie comme les versants nord dans le cas présent. Les données botaniques de la végétation actuelle indiquent que cette végétation est sensiblement proche de ce que nous rapporte l'anthracologie des charbonnières. Quelles sont les différences? Essentiellement la présence très significative du hêtre. Aujourd'hui, lorsque l'on parcourt les forêts de la Luzège, le hêtre est presque partout, dominant ou co-dominant dans des peuplements souvent vieillis, sinon abandonnés, il accompagne le chêne dans des futaies sur souches de mauvaises venues, des taillis sous futaies qui sont dégradés, ou bien même des taillis de bois de diamètre important. Dans la vallée de la Dordogne, le châtaignier est une espèce qui appartient également à la forêt charbonnée, alors qu'il est quasi inexistant dans les peuplements actuels. On le trouve bien sûr dans certaines pentes, mais n'est jamais structurant pour le paysage forestier. Le châtaignier pourrait constituer une essence favorisée par le charbonnage car facile à mener en taillis et de croissance bien plus rapide que le chêne, mais cela reste encore à confirmer.

En revanche, comme on pouvait s'y attendre, le châtaignier est très présent durant toute la période moderne aux confins Périgord-Limousin, dans l'ancienne châtaigneraie limousine. En effet, plusieurs charbonnières (sur les sites des Petites Forêts et de Goursaline), datées du XVII ${ }^{\mathrm{e}}$ s. $-\mathrm{XVIII}{ }^{\mathrm{e}} \mathrm{s}$. livrent des fragments de châtaignier, parfois exclusifs, ce qui incite à penser que le taillis monospécifique, formation forestière typique des paysages du XIX ${ }^{\mathrm{e}}$ s. (voir travaux de Pascal Plas) semble apparaitre plus tôt, et être antérieure d'un ou deux siècles au moins à son apogée.

\section{INDEX}

Index chronologique : Empire romain, ép. contemporaine, Temps Modernes, Moyen Âge operation Projet collectif de recherche (PCR) 


\section{AUTEURS}

\section{PHILIPPE ALLÉE}

SUP 